\title{
The Bdnf and Npas4 genes are targets of HDAC3-mediated transcriptional repression
}

\author{
Anto Sam Crosslee Louis Sam Titus ${ }^{1,5+}$, Dharmendra Sharma ${ }^{1,4+}$, Min Soo Kim² and Santosh R. D'Mello ${ }^{1,3^{*}}$ (1)
}

\begin{abstract}
Background: Histone deacetylase-3 (HDAC3) promotes neurodegeneration in various cell culture and in vivo models of neurodegeneration but the mechanism by which HDAC3 exerts neurotoxicity is not known. HDAC3 is known to be a transcriptional co-repressor. The goal of this study was to identify transcriptional targets of HDAC3 in an attempt to understand how it promotes neurodegeneration.

Results: We used chromatin immunoprecipitation analysis coupled with deep sequencing (ChIP-Seq) to identify potential targets of HDAC3 in cerebellar granule neurons. One of the genes identified was the activity-dependent and neuroprotective transcription factor, Neuronal PAS Domain Protein 4 (Npas4). We confirmed using ChIP that in healthy neurons HDAC3 associates weakly with the Npas4 promoter, however, this association is robustly increased in neurons primed to die. We find that HDAC3 also associates differentially with the brain-derived neurotrophic factor (Bdnf) gene promoter, with higher association in dying neurons. In contrast, association of HDAC3 with the promoters of other neuroprotective genes, including those encoding c-Fos, FoxP1 and Stat3, was barely detectable in both healthy and dying neurons. Overexpression of HDAC3 leads to a suppression of Npas4 and Bdnf expression in cortical neurons and treatment with RGFP966, a chemical inhibitor of HDAC3, resulted in upregulation of their expression. Expression of HDAC3 also repressed Npas4 and Bdnf promoter activity.
\end{abstract}

Conclusion: Our results suggest that Bdnf and Npas4 are transcriptional targets of Hdac3-mediated repression. HDAC3 inhibitors have been shown to protect against behavioral deficits and neuronal loss in mouse models of neurodegeneration and it is possible that these inhibitors work by upregulating neuroprotective genes like Bdnf and Npas4.

Keywords: HDAC3, Npas4, Bdnf, ChIP-Seq, Neurotoxic, Neurodegeneration

\section{Background}

Histone deacetylases (HDACs) are enzymes that deacetylate histones as well as a large number of other proteins in the nucleus, cytoplasm and mitochondria. The 18 HDACs expressed in mammals are divided into two subgroups based on sequence similarity and activation mechanism-classical HDACs (HDACs 1-11) and

\footnotetext{
*Correspondence: dmello@utdallas.edu; dmello9218@gmail.com

${ }^{\dagger}$ Anto Sam Crosslee Louis Sam Titus and Dharmendra Sharma

contributed equally to the manuscript

${ }^{3}$ Dallas, TX 75243, USA

Full list of author information is available at the end of the article
}

Sirtuins (Sirt1-7) [1-3]. Chemical inhibitors of classical HDACs protect against neurodegeneration in a variety of invertebrate and vertebrate models of neurodegenerative diseases, suggesting that aberrant activation of HDACs promote neuronal death, however, studies conducted on individual members of the HDAC family suggests a neuroprotective effect for some of them [4-7]. For example, HDAC4, HDAC6, HDAC7 and HDRP (a truncated form of HDAC9) protect neurons from death [4, 8-12]. Recently, we identified HDAC3 as a protein with high neurotoxic activity and found that it promotes neuronal death in cell culture models including a Huntington's disease (HD) model in which mutant huntingtin is

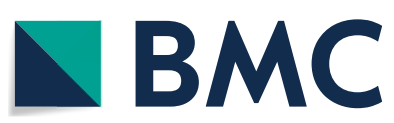

(c) The Author(s) 2019. This article is licensed under a Creative Commons Attribution 4.0 International License, which permits use, sharing, adaptation, distribution and reproduction in any medium or format, as long as you give appropriate credit to the original author(s) and the source, provide a link to the Creative Commons licence, and indicate if changes were made. The images or other third party material in this article are included in the article's Creative Commons licence, unless indicated otherwise in a credit line to the material. If material is not included in the article's Creative Commons licence and your intended use is not permitted by statutory regulation or exceeds the permitted use, you will need to obtain permission directly from the copyright holder. To view a copy of this licence, visit http://creativeco mmons.org/licenses/by/4.0/. The Creative Commons Public Domain Dedication waiver (http://creativecommons.org/publicdomain/ zero/1.0/) applies to the data made available in this article, unless otherwise stated in a credit line to the data. 
overexpressed [13-15]. This neurotoxic action of HDAC3 involves its phosphorylation by glycogen synthase kinase $3 \beta$ (GSK3 $\beta$ ) and interaction with HDAC1 [13]. Consistent with the requirement of HDAC3 in neurodegeneration is the finding of protection by HDAC1/HDAC3-selective inhibitors against neuropathology and behavioral deficits in mouse models of HD and Fredereich's ataxia [7, 16, 17]. HDAC3 orthologs have also been found to promote poly-Q toxicity in Drosophila and C. Elegans models of HD $[18,19]$. Recent studies have described that HDAC3 protects against optic nerve injury-induced retinal ganglion cell death and combines with LRRK2 to promote neuronal death in a PD model [20, 21]. Another group has described pharmacological inhibition of HDAC3 restores amyloid- $\beta$ induced impairment of plasticity [22].

While it is well accepted that HDAC3 has neurotoxic effects, how this is mediated is not known. It is known that Hdac3 represses gene transcription as part of the NCoR1/SMRT co-repressor complex [1-3]. It is therefore possible that HDAC3 promotes neurodegeneration by repressing the expression of genes that are required for neuronal survival or those genes that are stimulated in response to neurotoxic stimuli thereby protecting against them. While many targets of HDAC3 have been identified in non-neuronal tissue and cell types such as liver, macrophage and $\mathrm{T}$ cells [23-26], the genes regulated by HDAC3 in neurons or in the brain, particularly in the context of neurodegeneration, remain to be identified. To address this issue, we used ChIP-Seq to determine genome-wide binding of HDAC3 in healthy neurons and neurons primed to die. Among several others, our analysis identified the transcription factor, Neuronal PAS domain protein 4 (Npas4) and brain-derived neurotrophic factor (Bdnf), as potential targets for the HDAC3. Npas4 is an immediate early gene whose expression is strongly induced by neuronal activity. It regulates synaptic plasticity and learning and memory [27-29] and its dysfunction has been suggested to be involved in autism, bipolar disorder and cognitive disorders [3032]. Interestingly, Npas4 expression in the hippocampus is increased by excitotoxic and ischemic insults [27, 33, 34]. A growing body of evidence indicates that Npas4 has neuroprotective effects in cell culture and in vivo models of trophic factor deprivation, excitotoxicity, potassium cyanide neurotoxicity, ischemia, epilepsy and neuroinflammation [35-38]. Bdnf is a member of the neurotrophic family of neurotrophic factors [39]. Besides playing a key role in brain development and synaptic activity, Bdnf also promotes neuronal health and activity is believed to contribute to the pathogenesis of several neurodegenerative diseases [39-41]. The Bdnf gene has a complex structure with at least eight non-coding $5^{\prime}$ exons which are spliced to one $3^{\prime}$ coding exon. These transcripts are controlled by distinct promotors and differentially regulated by several cis-acting elements [42].

We describe validating the results of ChIP-Seq for Npas4 and Bdnf using standard ChIP assays. Furthermore, we show that forced expression of HDAC3 inhibits expression of Npas4 and Bdnf mRNAs, consistent with these genes being targets of HDAC3. Our results raise the possibility that the neurotoxic effect of HDAC3 is partly mediated through the reduction of the survivalpromoting action of Npas4 and Bdnf resulting from their transcriptional repression.

\section{Methods \\ Materials}

All cell culture media and reagents were purchased from Invitrogen and chemicals and reagents were from SigmaAldrich, unless stated otherwise. Poly-L-lysine from Trevigen was used to coat the plates for primary neuronal cultures. RGFP966, HDAC3 inhibitor (Sigma-Aldrich, catalog \#SML1652) was dissolved in DMSO and used at final concentration of $10 \mu \mathrm{g} / \mathrm{ml}$. The antibodies used for western blotting are as follows, Bdnf (Aviva Systems Biology, catalog \#ARP41970), ERK1/2 (Cell Signaling Technology, catalog \#9102), Npas4 (Kempbio, clone \#35-4) and HRP-conjugated secondary antibodies (Pierce). For ChIP analysis, Hdac3 antibody (Santa Cruz, catalog \#sc376957) was used. The primary antibodies were used at a dilution of 1:1000 and secondary antibodies were used at 1:20,000 dilution.

\section{Primary neuronal culture and treatments}

Wistar rats were used for all experiments. Founder rats were purchased from Charles River (Wilmington, MA) and housed to generate a colony within the institutional vivarium, which is run by dedicated staff and monitored by a veterinarian. The rats were maintained at $69^{\circ} \mathrm{F}$ with a light-dark cycle of $12 \mathrm{~h}$ day and $12 \mathrm{~h}$ night, with $18 \%$ protein rodent pellets (Envigo Teklad Global 2018) and water available ad libitum. For culturing of cerebellar granule cultures (CGNs), 7-8 day old pups were used. The pups were euthanized by carbon dioxide inhalation followed by rapid decapitation. For cortical neurons, embryos were extracted at gestation day 17. The pregnant dam was euthanized by carbon dioxide inhalation followed by rapid decapitation. After extraction, the embryos were euthanized by rapid decapitation [43].

CGNs, prepared from the cerebella of pups, were treated with either $25 \mathrm{mM} \mathrm{KCl}$ (high potassium, HK) or without $\mathrm{KCl}$ (low potassium, LK) for $6 \mathrm{~h}$ as described previously [43]. Briefly, cultures were grown in BME (Invitrogen) supplemented with 10\% FBS (Invitrogen). About $20 \mathrm{~h}$ after plating, the cultures were treated with $1 \mu \mathrm{M}$ of Ara-C to prevent mitotic cell proliferation. Both male 
and female rat pups were used for culturing neurons. For cortical neurons, the cortices of E17 embryos were dissociated with trypsin and the cells were plated in Neurobasal media with B27 supplements). Both male and female rat pups were used for culturing neurons. For pharmacological inhibition of HDAC3, $10 \mu \mathrm{M}$ of RGFP966 (Sigma) was added to the culture media.

\section{Adenovirus generation and infection}

The HDAC3 adenovirus was generated using ViraPower Adenovirus Expression Kit (Invitrogen) as previously described [44]. Briefly, crude viral lysate was purified by $\mathrm{CsCl}$ ultracentrifugation and the titer of the adenovirus was in the range of $10^{10}-10^{11} \mathrm{pfu} / \mathrm{ml}$. For infecting neurons with adenovirus, the conditioned media was collected and saved and the neurons were incubated with fresh media sufficient to cover the cell layer along with the virus. The plates were gently swirled every $15 \mathrm{~min}$ for $2 \mathrm{~h}$ after which the viral media was removed and the conditioned media was returned to the neurons [44]. The gene and protein expression analysis was performed after $28 \mathrm{~h}$.

\section{RNA preparation and gene expression analysis}

Total RNAs were extracted using Trizol reagent according to the manufacturer's guidelines. For reverse transcription, $1 \mu \mathrm{g}$ of total RNA was used, and cDNA was prepared using Verso cDNA synthesis kit (Thermo Scientific). Resulting cDNA was used as a template for PCR or qPCR analysis. Quantification of gene expression by RTqPCR was performed in the Bio-Rad Cycler using the iQ SYBR Green Supermix (Bio-Rad, catalog \#1708882). The primers used for qPCR are shown in Table 1 and the PCR amplification was performed as follows, initial denaturation $95^{\circ} \mathrm{C}$ for $2 \mathrm{~min}$ followed by denaturation at $95^{\circ} \mathrm{C}$ for $10 \mathrm{~s}$, annealing at $57^{\circ} \mathrm{C}$ for $15 \mathrm{~s}$ and extension at $72^{\circ} \mathrm{C}$ for $30 \mathrm{~s}$ for 40 cycles. Melt curve analysis was performed to verify the amplification of single PCR product. Actin was used as a normalization control and the relative expression levels of transcripts were calculated by the $2^{-\Delta \Delta C T}$ method.

\section{Chromatin immunoprecipitation (ChIP): 7-8 days after plating}

CGNs were subjected to serum-free HK or LK media as described previously. ChIP was performed as described previously [45]. Briefly, after treatment with HK or LK medium, the neurons were fixed in $1 \%$ formaldehyde for $10 \mathrm{~min}$ at room temperature. Fixation was stopped by adding glycine $(0.125 \mathrm{M})$. After washing twice in ice cold PBS, cells were scraped in PBS and centrifuged at $1500 \mathrm{rpm}$ for $10 \mathrm{~min}$. Pellets were suspended in $800 \mu \mathrm{l}$

Table 1 Primer pairs used for ChIP analysis and qPCR analysis

\begin{tabular}{|c|c|c|}
\hline \multicolumn{3}{|l|}{ ChIP analysis } \\
\hline Gene & Forward & Reverse \\
\hline Npas4 ChIP & 5' AGCCCCTTCTCATCCTTTGC & 5' CTTCCTTGCTTCCCGGTCTT \\
\hline Bdnf ChIP & 5' CACGGCTCTTCCTAGCACTT & 5' TGTTGATGAGACCCTTTCCATGT \\
\hline cFos ChIP & 5' AGTCTCATCCCCTGACCCTG & 5' CCTCAGCTGGCCGCTTTAT \\
\hline Foxp1 ChIP & 5' CTTGGAGGATGTTGCTCTGC & 5' GAGAGGAGGATTTCCAGAAGTT \\
\hline Stat3 ChIP & 5' GTAAGAGGCTCACGGTCTCG & 5' AACCGCTGAATTACAGCCCC \\
\hline \multicolumn{3}{|l|}{ qPCR analysis } \\
\hline Transcript & Forward & Reverse \\
\hline Bdnf exon I & 5'-CAGGGCAGTTGGACAGTCAT & 5'TACGCAAACGCCCTCATTCT \\
\hline Bdnf exon II & $5^{\prime}$ TTCGGCTCACACTGAGATCG & 5' CAGTATACCAACCCGGAGCTT \\
\hline Bdnf exon III & 5'TTGGAGGGCTCCTGCTTTCT & 5' CTGGGCTCAATGAAGCATCCAG \\
\hline Bdnf exon IV & 5' ACTGAAGGCGTGCGAGTATT & 5' TGGTGGCCGATATGTACTCC \\
\hline Bdnf exon $V$ & $5^{\prime}$ AAACCATAACCCCGCACACT & $5^{\prime}$ CTTCCCGCACCACAGAGCTA \\
\hline Bdnf exon VI & 5' GATGAGACCGGGTTCCCTCA & 5'TTGTTGTCACGCTCCTGGTC \\
\hline Bdnf exon VII & 5' ACTGTCACCTGCTTTCTAGGG & 5' GAGTTCCGCAGACCCTTTCA \\
\hline Bdnf exon VIII & 5' GTGCTCAGGCTAATCCTCGTT & 5' CTTTCTCCTGGGATGCACAGT \\
\hline Bdnf exon IXA & $5^{\prime}$ ACGGCGTGAACAGAGATCAT & 5' ACGGTTTCTAAGCAAGTGACG \\
\hline Npas4 & 5' CAGATCAACGCCGAGATTCG & 5' GACACCCTTGCGAGTGTAGAT \\
\hline Actin & 5' GCCATGTACGTAGCCATCCA & 5' GGAGCGCGTAACCCTCATAG \\
\hline
\end{tabular}

Table lists the primers used for ChIP and qPCR analysis. The exon specific Bdnf primers described in Nair et al. [83] were used for the analysis 
of buffer 1 (50 mM Hepes-KOH, pH 7.5; $140 \mathrm{mM} \mathrm{Nacl}$; 1 mM EDTA pH 8; 10\% Glycerol; 0.5\% NP-40; 0.25\% Triton X-100; supplemented with $1 \mathrm{mM}$ PMSF; and Protease inhibitor cocktail). Cells were lysed for $10 \mathrm{~min}$ on ice and nuclei were pelleted by centrifugation at 3000 RPM for $10 \mathrm{~min}$. After washing the nuclei once with buffer 2 (200 mM Nacl; 1 mM EDTA pH 8; 0.5 mM EGTA, pH 8; $10 \mathrm{mM}$ Tris Hcl, pH 8 supplemented with $1 \mathrm{mM}$ PMSF; and Protease inhibitor cocktail), sonication was performed in buffer 3 (1 mM EDTA, pH 8; 0.5 mM EGTA, $\mathrm{pH} 8 ; 10 \mathrm{mM}$ Tris $\mathrm{HCl}, \mathrm{pH}$ 8.1; 0.5\% SDS supplemented with $1 \mathrm{mM}$ PMSF and Protease inhibitor cocktail). Chromatin was sonicated to a size range of $100-300 \mathrm{bp}$ fragments for ChIP-Seq and 800-1000 bp fragments for normal ChIP analysis. Samples were centrifuged at $13,000 \mathrm{rpm}$ for $15 \mathrm{~min}$ at $4{ }^{\circ} \mathrm{C}$. One hundred micrograms of chromatin was used for each ChIP analysis. Samples were incubated overnight with 3-5 $\mu \mathrm{l}$ of antibody $(1 \mu \mathrm{g} /$ $\mu \mathrm{l})$. Precipitation and washing of chromatin samples has been described earlier. Finally, DNA was suspended in $60 \mu \mathrm{l}$ of $10 \mathrm{mM}$ Tris, $\mathrm{pH}$ 7.5. For PCR, $3 \mu \mathrm{l}$ of template DNA was used for amplification. The promoter primer sequences used are provided in Table 1.

\section{ChIP-Seq and data analysis}

For sequencing, ChIP was performed as described earlier and immunoprecipitated DNA was used for the library construction using NEB Next kit (New England Bio Labs). Library prepped DNA samples were sequenced on an Illumina HiSeq 2000 at the University of Southwestern Medical Center sequencing facility using default parameters (single end, forward sequencing). Quality assessment of the raw sequencing reads was done using NGS-QCToolkit. Sequencing reads with quality score under Phred Score $<20$ were discarded. The quality filtered reads were then aligned to rat reference genome RGSC_v3.4 (rn4) using Bowtie2 (v 2.0.6) aligner. Transcription factor binding sites were identified using the peak calling algorithm QuEST [46]. QuEST employs a kernel density estimation approach to determine positions where protein complexes contact DNA. Peaks were called for regions with fold change values greater than three and q-value obtained by Bonferroni correction of p-values greater than 0.00001 . Once peak regions were called, the HOMER pipeline was used to annotate the peaks. Direct quantitative comparison in HK and LK samples was done using MAnorm. Based on the assumption that most common peaks should be the same between two ChIP-Seq samples, MAnorm first normalizes all the peaks based on a robust regression model and then identifies those peaks which are statistically significantly expressed in one sample compared to the other.

\section{Luciferase assay}

For generating the Npas4-Luciferase construct, the genomic fragment from $-2 \mathrm{~kb}$ to $+100 \mathrm{~b}$ of Npas4 gene was amplified using primers and cloned into PGL3-basic vector (Promega) using the $\mathrm{Xhol} /$ HindIII restriction sites. For the Bdnf-Luciferase construct, a $500 \mathrm{~b}$ genomic fragment was amplified and cloned using the ChIP primers mentioned in Table 1. For checking the promoter activity, HT22 cells were transfected with $4 \mu \mathrm{g}$ of either HDAC3 or GFP plasmids, along with $4 \mu \mathrm{g}$ of the promoter plasmid in PGL3-firefly luciferase and $0.4 \mu \mathrm{g}$ of plasmid of renilla luciferase plasmid to normalizing the transfection efficiency. The luciferase activity was measured using the Promega Dual Luciferase Reporter System and the relative luminescence units (RLU) obtained with firefly luciferase were normalized with the RLU of renilla luciferase.

\section{Statistical analysis}

The data analysis and generation of graphs were done using GraphPad Prism 5 software. The intensity of bands was quantified using ImageJ. Statistical analysis was performed using two-tailed Student t-test for comparing two groups and for multiple group comparisons, ANOVA analysis was performed. The significance levels are indicated based on the p-value as follows, ${ }^{*}<0.05, * *<0.01$, $* *<0.001$. The results are displayed as mean \pm SD.

\section{Results \\ Genome wide mapping of $\mathrm{Hdac} 3$ binding}

Cultured CGNs undergo apoptosis when switched from medium containing depolarizing levels of potassium (HK medium) to non-depolarizing medium (LK) [47]. Using this widely utilized model of neuronal apoptosis we showed that forced expression of HDAC3 induces death of otherwise healthy neurons (treated with HK medium) and greatly exacerbated the extent of death in LK. As a step towards identification of transcriptional targets of HDAC3 that regulate its neurotoxic activity, we used three independent sets of HK and LK treated CGNs. RNA from sister cultures were subjected to RT-PCR analysis to confirm that the expression of genes known to be altered in this paradigm, such as the upregulation of c-jun, were indeed altered (data not shown). After this "quality control" step, the cultures were processed for ChIP-Seq analysis. To correct genomic copy number variations and sonication introduced fragment bias, input control (chromatin taken before immunoprecipitation) was used. Table 2 shows the details of the mapping statistics. Using criteria of fold change greater than three and FDR less than 0.00001 a total number of 34,450 and 23,850 genomic 
Table 2 ChIP-Seq read analysis

\begin{tabular}{llccc}
\hline Sample & Raw read count & Unique read count & Mapped read count & $\begin{array}{c}\text { Mapping } \\
\text { rate (\%) }\end{array}$ \\
\hline HK & $28,649,979$ & $11,631,206$ & $8,640,236$ & 74 \\
HK_input & $25,431,774$ & $20,338,856$ & $15,224,517$ & 75 \\
LK_H3 & $29,817,952$ & $12,785,551$ & $9,500,783$ & 74 \\
LK_input & $14,549,174$ & $11,003,800$ & $5,934,983$ & 54 \\
\hline
\end{tabular}

Table contains the number and percentage of high quality uniquely mapped reads. Reads that were assigned uniquely to the rat genome were used in the analysis

binding sites for HDAC3 were revealed in HK and LK respectively. Binding sites were grouped depending on their position relative to the nearest gene. Figure 1a, b shows the distribution of these sites in the whole genome. Overall, HDAC3 was preferentially associated with intergenic and intronic regions. Others have also shown maximum enrichment of transcription factors and co-regulators including HDAC3 in intergenic and intronic regions [48, 49]. To identify transcriptional targets of the HDAC3, we focused on around $2 \mathrm{~kb}$ upstream TSS region of the nearest gene, considered as promoter, and found 224 and 137 high occupancy sites in HK and LK respectively (Fig. 1a, b). Table 3 shows some of the neuronal genes with HDAC3 binding in the promoter region. A detail list of all the binding sites is listed in Additional file 1: Table S1 and Additional file 2: Table S2. Next, we analyzed important functional groups of genes that show increased HDAC3 binding at their promoter region and did the gene ontology (GO) terms enrichments. Top GO analysis for the genes promoter bound with HDAC3 include enrichment of GO terms specific for neuronal functions. These include neuron projection development, system development, vesicle mediated transport, ion transport, signal transduction, and regulation of cell communication etc. (Fig. 1c, d). Details of all the GO terms are given as a separate excel sheet in Additional file 3: Table S3A, B.

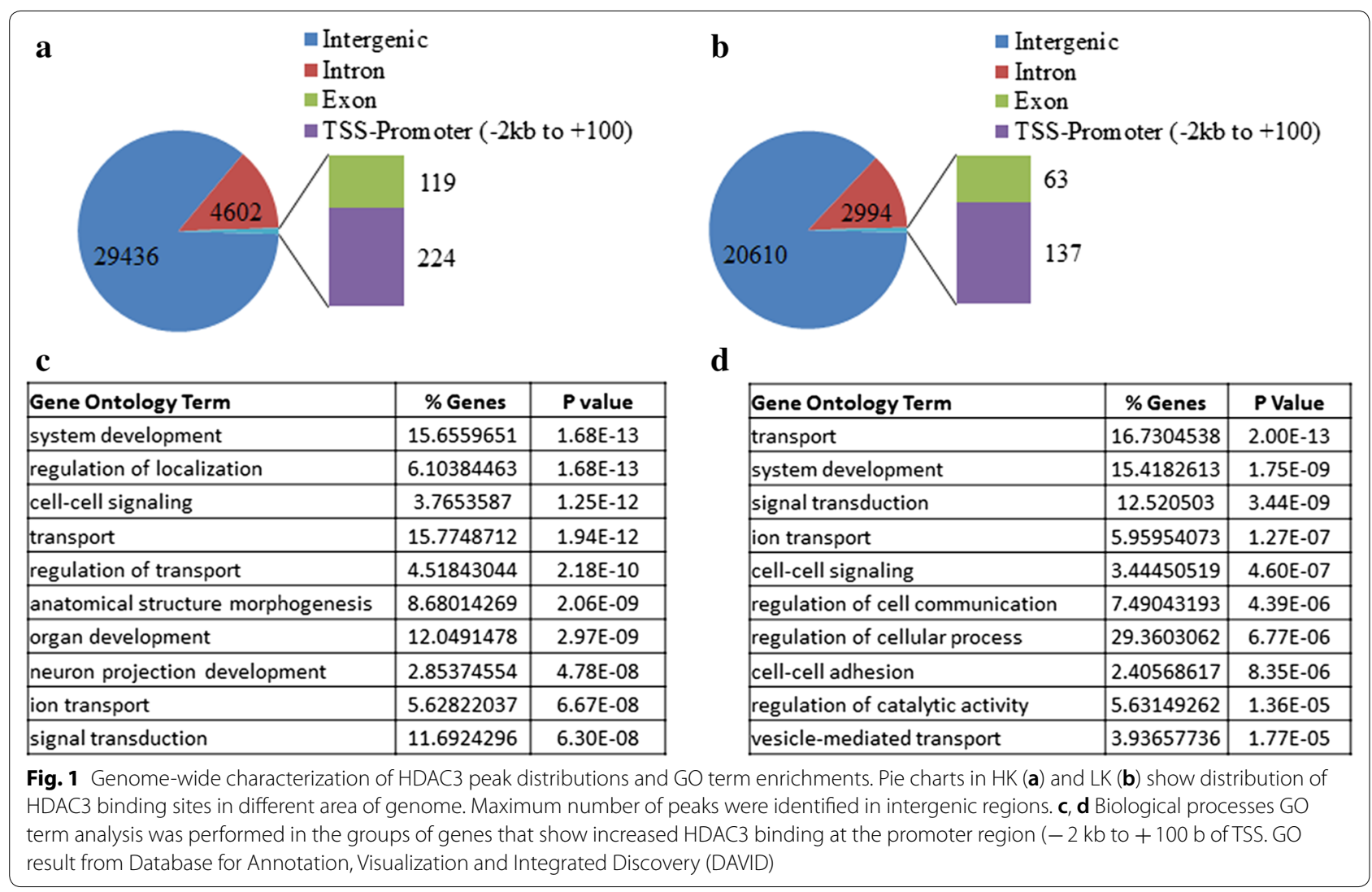


Table 3 Genes with HDAC3 binding sites in cerebellar granule neurons

\begin{tabular}{|c|c|c|c|}
\hline Gene symbol & Gene details & Distance to nearest TSS & $\begin{array}{l}\text { Binding } \\
\text { in HK/ } \\
\text { LK }\end{array}$ \\
\hline $\mathrm{Nr3c2}$ & Nuclear receptor subfamily 3 , group C, member 2 & -2023 & $\mathrm{HK}$ \\
\hline Npy2r & Neuropeptide Y receptor Y2 & -1951 & HK \\
\hline Opa3 & Optic atrophy 3 & -1853 & HK \\
\hline Neurod2 & Neuronal differentiation 2 & -1583 & $\mathrm{HK}$ \\
\hline Hes1 & hes family bHLH transcription factor 1 & -1363 & LK \\
\hline Npas4 & Neuronal PAS domain protein 4 & -1063 & HK \\
\hline $\mathrm{BC}|2| 10$ & BCL2-like 10 (apoptosis facilitator) & -1051 & LK \\
\hline Bdnf & Brain-derived neurotrophic factor & -1015 & LK \\
\hline Hrk & Harakiri, BCL2 interacting protein & -917 & LK \\
\hline Fadd & Fas (TNFRSF6)-associated via death domain & -900 & HK \\
\hline Nptxr & Neuronal pentraxin receptor & -890 & $\mathrm{HK}$ \\
\hline Clqa & Complement component 1, q subcomponent, A chain & -874 & $\mathrm{HK}$ \\
\hline Nmnat2 & Nicotinamide nucleotide adenylyltransferase 2 & -868 & $\mathrm{HK}$ \\
\hline Bid & $\mathrm{BH} 3$ interacting domain death agonist & -824 & LK \\
\hline Rhebl1 & Ras homolog enriched in brain like 1 & -687 & LK \\
\hline Grip1 & Glutamate receptor interacting protein 1 & -375 & LK \\
\hline Klf10 & Kruppel-like factor 10 & -362 & HK \\
\hline Diablo & Diablo, IAP-binding mitochondrial protein & -284 & LK \\
\hline Grm4 & Glutamate receptor, metabotropic 4 & -259 & HK \\
\hline Npffr1 & Neuropeptide FF receptor 1 & -202 & LK \\
\hline Tgfb1 & Transforming growth factor, beta 1 & -112 & LK \\
\hline Syngr1 & Synaptogyrin 1 & -87 & LK \\
\hline Plxnd1 & Plexin D1 & -45 & HK \\
\hline Gabarap & GABA(A) receptor-associated protein & -31 & HK \\
\hline App & Amyloid beta (A4) precursor protein & 52 & LK \\
\hline Snapin & SNAP-associated protein & 58 & $\mathrm{HK}$ \\
\hline
\end{tabular}

Table lists some of the neuronal genes with HDAC3 binding site in the promoter region. The genes are sorted based on the distance of the binding site from the TSS

\section{Promoter occupancy of Hdac3 and gene expression analysis}

We previously reported the results of a RNA-Seq study identifying differentially expressed genes in CGNs treated with HK and LK [43]. We used that dataset and compared the promoter binding data of HDAC3 from the current study to identify the overlapping genes. The results of this comparison are shown in Fig. 2a, b. Overall under HK condition, out of 224 genes that were showing HDAC3 promoter occupancy, only 58 genes showed differential expression (26 down and 32 up regulated). Similarly, in LK condition, from a list of 137 genes, only 41 showed differential expression (18 down and 23 up regulated). An Excel spreadsheet containing this information is provided (Additional file 4: Table S4). It is likely that genes that overlap are regulated by HDAC3 or that their expression change is the consequence of HDAC3 action on direct targets.

\section{Validation of ChIP Seq analysis}

To validate the ChIP-Seq data we selected two genes showing positive binding in the promoter region, Npas4 and Bdnf, and conducted standard ChIP-PCR assays. These genes were analyzed along with three other genes that are also known to have neuroprotective effects but were not among the genes identified in the ChIP Seq analysis-the neuronal activity-depended gene c-Fos, the neuroprotective Forkhead protein FoxP1, and the Stat3 transcription factor. ChIP was conducted using CGN cultures treated with HK or LK medium and focusing on the region spanning about $1000 \mathrm{bp}$ upstream of the transcription-start site region. HDAC3 occupancy was detectable at the promoter region of the Npas4 and Bdnf genes. Both genes showed HDAC3 occupancy in $\mathrm{HK}$ and the enrichment robustly increased in LK (Fig. 3). In contrast, association of HDAC3 with the promoters of the other three genes, cFos, FoxP1 and Stat 3 was not 
a

\section{Genes with Peaks \\ in Promoter \\ Region in $\mathrm{HK}$}

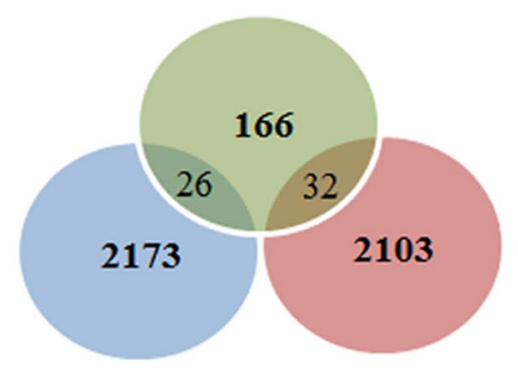

Downregulated

in $\mathrm{HK}$

\begin{abstract}
Upregulated
in $\mathrm{HK}$
\end{abstract}

b

\section{Genes with Peaks \\ in Promoter \\ Region in LK}

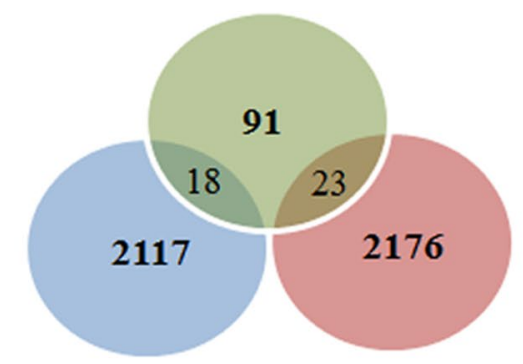

Downregulated
in $\mathrm{LK}$

\section{Upregulated \\ in $\mathrm{LK}$}

Fig. 2 Integrative analysis of ChIP-Seq and RNA-Seq data [43] identifies multiple HDAC3 targets in HK and LK. Venn diagram shows HDAC3 occupancy at the promoter region of differentially-expressed genes in either HK (a) or LK (b) condition. List of differentially-expressed genes during neuronal death [43] was used and overlapping was performed between the number of genes up or down regulated having HDAC3 occupancy at the promoter

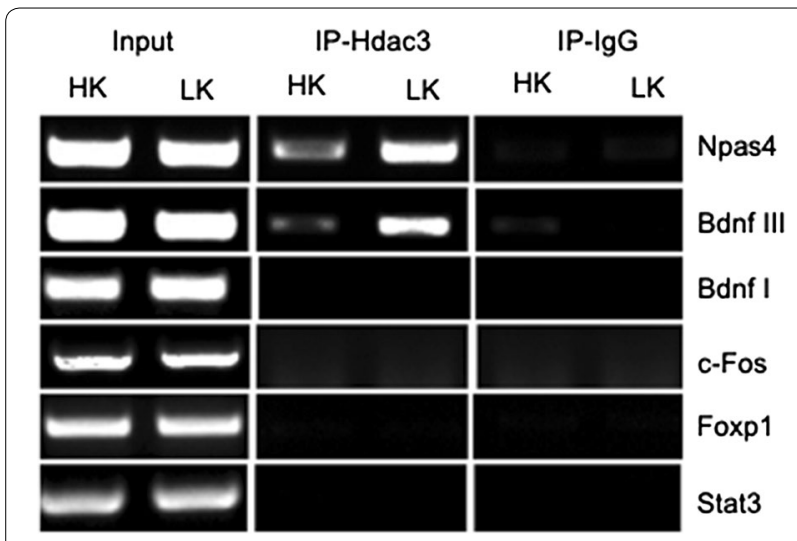

Fig. 3 PCR validation of ChIP-Seq data. ChIP was used to validate the ChIP-Seq results. For this, ChIP was conducted on genes that were positive for HDAC3 occupancy based on ChIP-Seq (Npas4 and Bdnf) and three genes known to have neuroprotective effects but were not among the positive hits in the ChIP-Seq (CFos, FoxP1, Stat3). PCR was conducted following immunoprecipitation of sheared chromatin using primers to the promoter regions of these genes (see Table 1 for primer sequences)

detectable either in HK or LK. Bdnf genomic structure contains multiple promoters, used to generate different transcripts [42]. The best characterized Bdnf promoter is immediately upstream of the rat exon III, which corresponds to the mouse Bdnf exon IV promoter [50]. For our studies this Bdnf III promoter, cloned from rat genomic DNA, was used since it is shown to be activated upon membrane depolarization in cultured cortical and hippocampal neurons by means of $\mathrm{KCl}(50 \mathrm{mM})$ treatment
[51-54]. We also analyzed Bdnf I promoter and found out that the HDAC3 enrichment was specific to the Bdnf III promoter as there was no binding seen on the Bdnf I promoter (Fig. 3). Although limited in scope, these findings indicate that the ChIP-Seq analyses accurately identified genes that were bound by HDAC3.

\section{Npas4 and Bdnf expression is negatively regulated by HDAC 3 in neurons}

To examine if association of HDAC3 with the Npas4 and Bdnf gene promoters resulted in altered expression, we overexpressed HDAC3 in cortical neurons using adenovirus and evaluated its effect on Npas4 and Bdnf gene expression. Since extended overexpression of HDAC3 kills cortical neurons [15], we limited expression to $28 \mathrm{~h}$. Both Bdnf and Npas4 mRNA levels were downregulated by HDAC3 (Fig. 4a, b). The downregulation of Bdnf was also detected at the protein level (Fig. 4c, d). Due to the very low expression of Npas4 under basal conditions we could not detect the reduction of Npas4 protein.

To confirm that Npas4 and Bdnf are targets of HDAC3 we treated cortical neurons with RGFP966, a chemical inhibitor of HDAC3. It is well established that RGFP inhibits HDAC3 highly selectively and effectively both in cell culture and in vivo [17, 20,22]. We found an upregulation of Npas4 (Fig. 5) and Bdnf (Fig. 6) expression at the mRNA and protein level following treatment of neurons with RGFP966. We also analyzed various transcripts of Bdnf using exon specific primers and found that the transcripts corresponding to exons III, IV, VI and IXA of the Bdnf gene were the most induced by HDAC3 inhibition. 

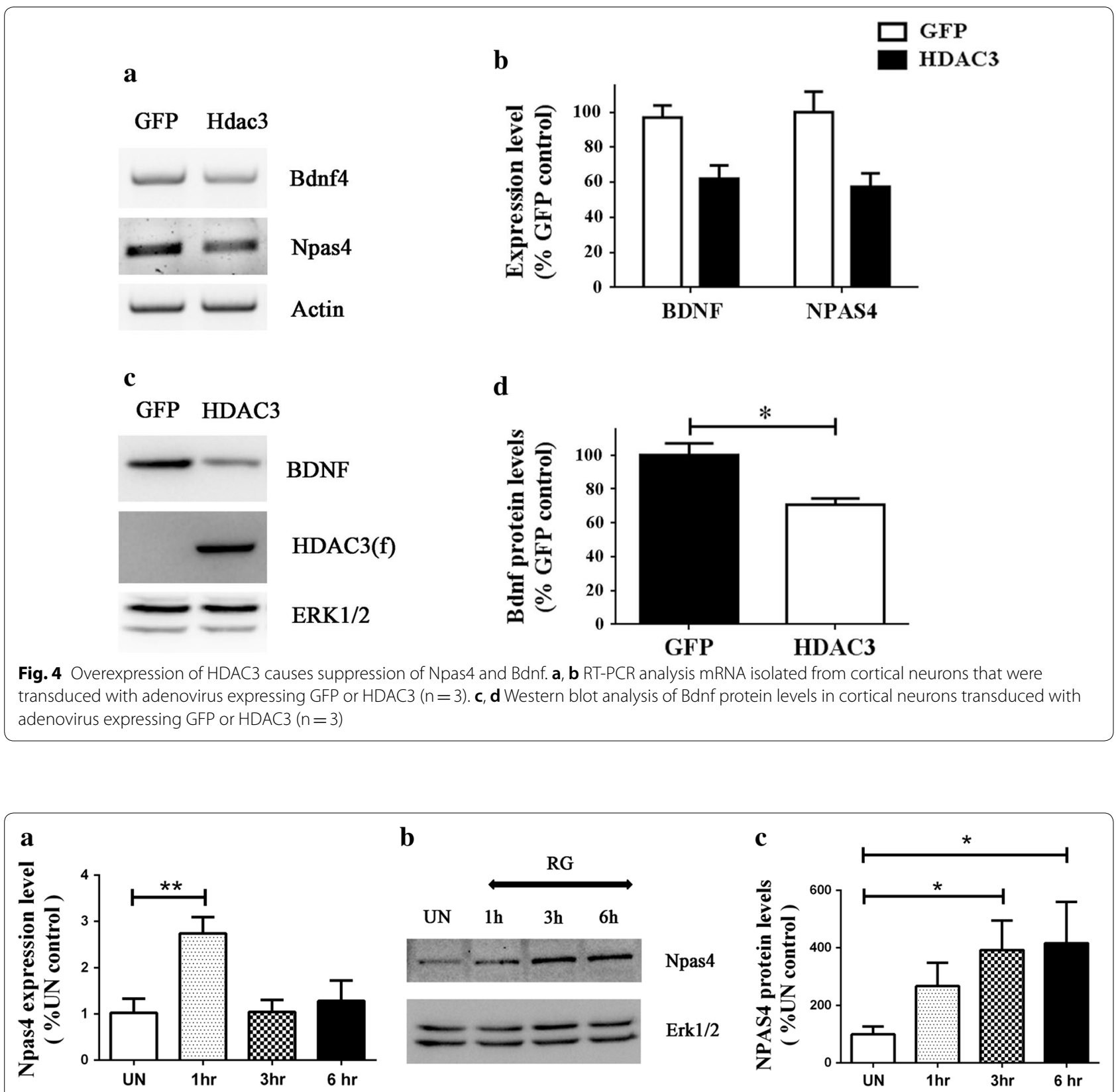

Fig. 5 Inhibition of HDAC3 by RGFP966 stimulates Npas4 expression. a Cortical neurons were treated with $10 \mu M$ RGFP966 and the expression levels of Npas 4 was determined at different time points by qPCR $(n=3)$ and the protein levels were also analyzed by western blotting $(\mathbf{b}, \mathbf{c})(n=3)$

Lastly, we performed transcriptional activity assays using the Npas4 and Bdnf III promoters fused to luciferase reporter in the pGL3-basic vector. As shown in Fig. 7, co-expression of HDAC3 reduced the activity of both the Npas4 and Bdnf III promoters. Taken together, the results of our ChIP assays, expression analyses, pharmacological treatment and promoter activity analysis indicate that the Npas4 and Bdnf genes are transcriptionally repressed by HDAC3.

\section{Discussion}

Forced expression of HDAC3 promotes death of neuronal cells, but not of non-neuronal cell types [15] suggesting unique targets of HDAC3 in neurons that are regulated during neuronal death. Transcriptional targets of HDAC3 have been described in non-neuronal systems [23-25]. However, considering the role of HDAC3 in brain, its targets in healthy and apoptotic neurons have not been previously described. Our ChIP-Seq analysis 


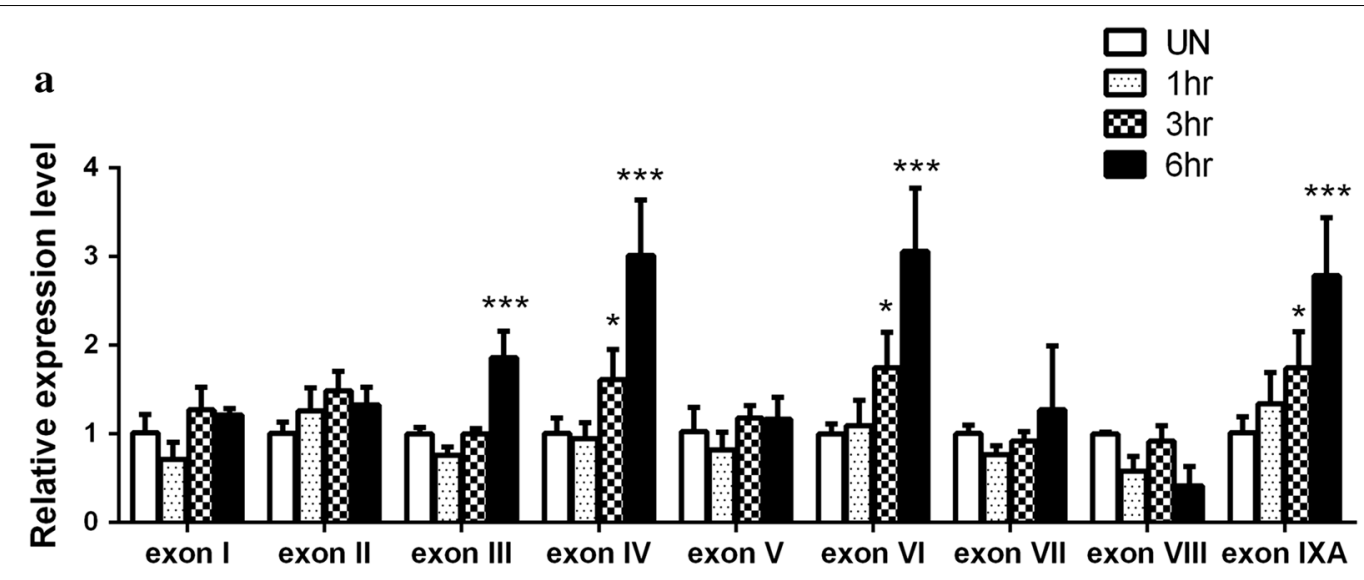

b
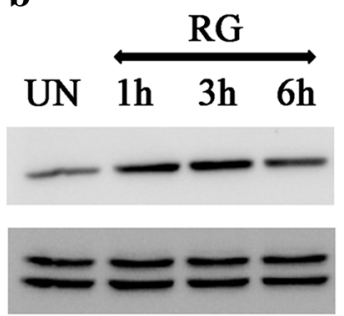

Bdnf

Erk1/2

c

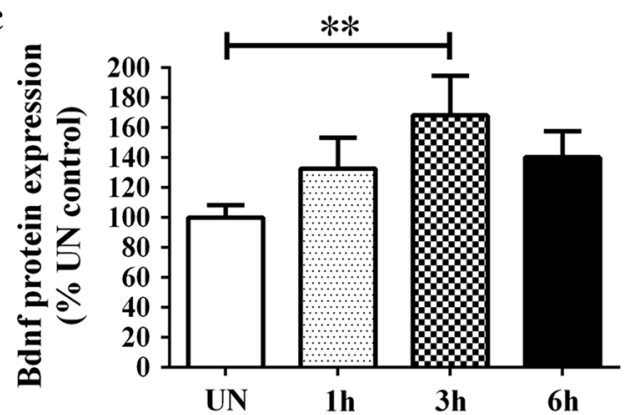

Fig. 6 Inhibition of HDAC3 by RGFP966 causes upregulation of specific Bdnf exons. a Cortical neurons treated with RGFP966 were analyzed with exon specific primers for Bdnf [83] and a significant upregulation was observed in exons III, IV, VI and IXA $(n=3)$. b, c The protein levels were analyzed by western blotting which shows an increase in Bdnf expression $(n=3)$
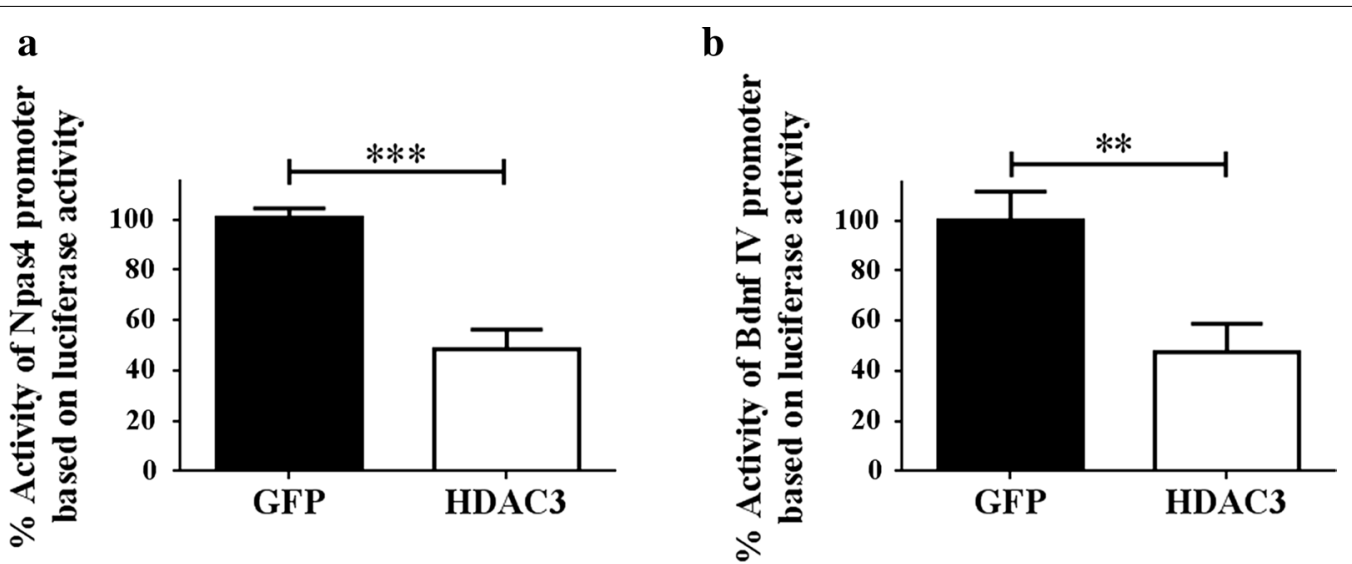

Fig. 7 HT22 cells were transfected with either GFP or HDAC3 plasmids along with renilla luciferase and PGL3-basic vector with the promoter sequence of $\mathbf{a}$ Npas 4 or $\mathbf{b}$ Bdnf. The RLU values of firefly luciferase obtained were normalized with the RLU of renilla luciferase and the promoter activity is expressed as percentage of the activity observed in GFP transfected control $(n=3)$

has identified several potential HDAC3 targets of which we have followed up on two, Npas4 and Bdnf. Expression of both these genes is stimulated by neuronal activity. More importantly, both genes have been shown to have neuroprotective actions. This is particularly true for Bdnf for which neuroprotective effects have been amply demonstrated in a variety of cell culture and in vivo models of neurodegenerative disease [39-41]. 
It is important to mention here that in our ChIP-Seq analysis, we could not detect HDAC3 peak at the NPAS4 promoter in LK, however, repeated ChIP-PCR validation data clearly showed that HDAC3 was not only present at the promoter in LK condition, its binding was highly increased. At present, we don't have clear explanation for this discrepancy, however, it is possible that under LK condition, neurons are primed to undergo apoptosis that may lead to increased background noise resulting in the loss of important information.

Although one of several IEGs induced by neuronal activity, Npas4 is different from the other activityinduced genes in that it is expressed specifically in neurons and its expression is not increased by other extracellular stimuli, such as growth and neurotophic factors $[55,56]$. The mechanisms regulating transcription of several IEGs including Npas4 in neurons reveal that the machinery required for transcription initiation is in place at the promoter even in the absence of neuronal activity but RNA polymerase stalls just downstream of the transcription start site [57]. A recent report revealed that in the absence of neuronal activity the conformation of chromatin stearically hinders the activation of transcription of these genes [58]. Double-strand breaks formation within the upstream regions following stimulation of neuronal activity relieves this hindrance permitting preassembled transcriptional machinery to transcribe these genes [58]. We propose that another factor contributing to suppression of Npas4 gene transcription is HDAC3. Interestingly, HDAC3 does not associate appreciably with the promoter region of the c-Fos gene suggesting that neuronal activity stimulates the Npas4 and c-Fos genes by different mechanisms.

Results of other studies indicate that the Bdnf gene is a target of Npas4 [27, 59, 60]. Indeed, Npas4 has been found to associate with the mouse Bdnf-I and Bdnf-IV (similar to rat Bdnf III) promoters, which are also activated by neuronal activity [27]. This explains the delayed induction of Bdnf expression in comparison to the increase in Npas4 transcription following neuronal excitation [27]. We find the Bdnf III promoter, but not the Bdnf-I promoter, is bound by HDAC3 suggesting that the expression of these two Bdnf transcripts may also be subject to different regulatory mechanisms. Interestingly, this Bdnf promoter is selectively downregulated in Huntington's disease and other neurodegenerative conditions [61]. Our finding that HDAC3 downregulates Bdnf expression appears to contradict a recent report which described that HDAC3 is recruited to the Bdnf promoter by MeCP2 [62]. However, the authors of that study found that Bdnf is reduced in HDAC3 conditional knock out mice suggesting that HDAC3 positively regulates Bdnf gene transcription [62]. There have also been studies where Bdnf was found to be repressed by HDAC3 [63-65]. It is possible that whether HDAC3 suppresses or stimulates Bdnf expression may depend on the transcriptional regulators it associates with at the Bdnf promoter. We previously described that in HD-related neurodegeneration HDAC3 disassociates with normal huntingtin and associates with HDAC1 [13, 14]. Moreover, HDAC3 requires phosphorylation by GSK3 $\beta$ to become neurotoxic [15].

Association of HDAC3 with the Npas4 and Bdnf gene promoters is robustly elevated in CGNs treated with LK. This may explain the reduction of expression of the Npas4 and Bdnf mRNAs in neurons primed to die. Given that both genes have protective effects in many different models [34, 37, 66], the inhibition of their expression by HDAC3 might explain its neurotoxic effect. Indeed, extracellular Bdnf has been shown to protect CGNs from LK-induce death [67-71].

In addition to their roles in neuroprotection, both Npas4 and Bdnf enhance learning and memory and cognitive function [29, 72-74]. Interestingly, elevating HDAC3 expression negatively regulates learning and memory whereas ablation of the HDAC3 gene or pharmacological inhibition of HDAC3 restores it [75-78]. It is possible that the negative effect of HDAC3 on learning and memory is also mediated by the transcriptional repression of Npas4 and Bdnf.

\section{Conclusion}

We provide evidence indicating that Npas4 and Bdnf, two genes that have critical roles in brain development and function, are transcriptional targets of HDAC3-mediated repression. HDAC3 inhibitors have been shown to protect against behavioral deficits and neuronal loss in mouse models of neurodegeneration [7, 17, 79-81]. It is possible that these effects involve upregulation of Npas4 and Bdnf, both of which have been described to be neuroprotective. We recently described that genetic ablation of HDAC3 itself affects brain development [82]. Further work is needed to determine whether these effects on brain development involve deregulation of Npas4 and Bdnf gene expression.

\section{Supplementary information}

Supplementary information accompanies this paper at https://doi. org/10.1186/s12868-019-0546-0.

Additional file 1: Table S1. Unique HDAC3 Peaks in the promoter region in HK. Table shows a list of putative transcriptional targets of HDAC3 in HK. Genes were grouped based on the enrichment of HDAC3 in their promoter region. An area of around $2 \mathrm{~kb}$ upstream of the TSS was considered as promoter.

Additional file 2: Table S2. Unique HDAC3 Peaks in the promoter region in LK. Table shows a list of putative transcriptional targets of HDAC3 in LK. 
Genes were grouped based on the enrichment of HDAC3 in their promoter region. An area of around $2 \mathrm{~kb}$ upstream of the TSS was considered as promoter.

Additional file 3: Table S3. Biological Process-Gene Ontology. List of putative transcriptional targets of HDAC3 in HK (A) and in LK (S3B) were subjected to DAVID and functional annotation was performed. $p$ value and benjamini FDR were calculated and the genes were categorized based on their cellular function.

Additional file 4: Table S4. DEGs having HDAC3 peaks in promoter region. Previously published data [77] of differentially-expressed genes during neuronal death was utilized and overlapping analysis with the ChIP-Seq data was performed to get the expression of genes having HDAC3 occupancy at the promoter. S4A shows genes in HK, and S4B shows genes having differential expression in LK.

\section{Abbreviations}

HDAC3: histone deacetylase-3; Bdnf: brain-derived neurotrophic factor; Npas4: neuronal PAS domain protein 4; ChIP-Seq: chromatin immunoprecipitationsequencing; HK: high potassium; LK: low potassium; CGNs: cerebellar granule neurons.

\section{Acknowledgements}

The authors also wish to thank Dr. Zhe Qu for the use of the HDAC3-Flag virus that she generated and which was used in some of the experiments.

\section{Authors' contributions}

SRD supervised the project. SRD, DS, ASCLST designed the experiments. DS and ASCLST performed the experiments. DS, ASCLST and MSK analyzed the data. DS and SRD wrote the manuscript. All authors read and approved the final manuscript.

\section{Funding}

This research was funded by the National Institutes of Health Grant R01 NS040408 to SRD.

\section{Availability of data and materials}

All reagents generated as part of this study are available on request. All data is published in the manuscript and additional results.

\section{Ethics approval and consent to participate}

All animal-related experiments were approved by the institutional animal care and use committee (IACUC) of Southern Methodist University (Protocol A14007) and performed in strict accordance with $\mathrm{NIH}$ guidelines. All efforts were made to minimize the number of animals used.

\section{Consent to publish}

Not applicable.

\section{Competing interests}

The authors declare that they have no competing interests.

\section{Author details}

${ }^{1}$ Department of Biological Sciences, Southern Methodist University, Dallas, TX, USA. ${ }^{2}$ Quantitative Biomedical Research Center, University of Texas Southwestern Medical Center, Dallas, TX, USA. ${ }^{3}$ Dallas, TX 75243, USA. ${ }^{4}$ Present Address: Department of Molecular and Cell Biology, Baylor College of Medicine, Houston, TX, USA. ${ }^{5}$ Present Address: Department of Biomedical Engineering, University of Houston, Houston, TX, USA.

\section{Received: 7 January 2019 Accepted: 18 December 2019} Published online: 28 December 2019

\section{References}

1. Gregoretti IV, Lee YM, Goodson HV. Molecular evolution of the histone deacetylase family: functional implications of phylogenetic analysis. J Mol Biol. 2004;338:17-31.
2. Haberland M, Montgomery RL, Olson EN. The many roles of histone deacetylases in development and physiology: implications for disease and therapy. Nat Rev Genet. 2009;10:32-42.

3. Yang XJ, Seto E. The Rpd3/Hda1 family of lysine deacetylases: from bacteria and yeast to mice and men. Nat Rev Mol Cell Biol. 2008;9:206-18.

4. D'Mello SR. Histone deacetylases as targets for the treatment of human neurodegenerative diseases. Drug News Perspect. 2009:22:513.

5. Taylor DM, Maxwell MM, Luthi-Carter R, Kazantsev AG. Biological and potential therapeutic roles of sirtuin deacetylases. Cell Mol Life Sci. 2008;65:4000-18

6. Sleiman SF, Basso M, Mahishi L, Kozikowski AP, Donohoe ME, Langley B, Ratan RR. Putting the 'HAT'back on survival signalling: the promises and challenges of HDAC inhibition in the treatment of neurological conditions. Expert Opin Investig Drugs. 2009;18:573-84.

7. Thomas EA, Coppola G, Desplats PA, Tang B, Soragni E, Burnett R, Gao F, Fitzgerald KM, Borok JF, Herman D, Geschwind DH, Gottesfeld JM. The HDAC inhibitor $4 \mathrm{~b}$ ameliorates the disease phenotype and transcriptional abnormalities in Huntington's disease transgenic mice. Proc Natl Acad Sci USA. 2008;105:15564-9.

8. Majdzadeh N, Wang L, Morrison BE, Bassel-Duby R, Olson EN, D'Mello SR. HDAC4 inhibits cell-cycle progression and protects neurons from cell death. Dev Neurobiol. 2008;68:1076-92.

9. Ma C, D'Mello SR. Neuroprotection by histone deacetylase-7 (HDAC7) occurs by inhibition of c-jun expression through a deacetylase-independent mechanism. J Biol Chem. 2011;286:4819-28.

10. Morrison BE, Majdzadeh N, Zhang X, Lyles A, Bassel-Duby R, Olson EN, D'Mello SR. Neuroprotection by histone deacetylase-related protein. Mol Cell Biol. 2006;26:3550-64.

11. Pandey UB, Nie Z, Batlevi Y, McCray BA, Ritson GP, Nedelsky NB, Schwartz SL, DiProspero NA, Knight MA, Schuldiner O, Padmanabhan R, Hild M, Berry DL, Garza D, Hubbert CC, Yao TP, Baehrecke EH, Taylor JP. HDAC6 rescues neurodegeneration and provides an essential link between autophagy and the UPS. Nature. 2007:447:859-63.

12. Iwata A, Riley BE, Johnston JA, Kopito RR. HDAC6 and microtubules are required for autophagic degradation of aggregated huntingtin. J Biol Chem. 2005;280:40282-92.

13. Bardai FH, Price V, Zaayman M, Wang L, D'Mello SR. Histone deacetylase-1 (HDAC 1) is a molecular switch between neuronal survival and death. J Biol Chem. 2012;287:35444-53.

14. Bardai FH, Verma P, Smith C, Rawat V, Wang L, D'Mello SR. Disassociation of histone deacetylase-3 from normal huntingtin underlies mutant huntingtin neurotoxicity. J Neurosci. 2013;33:11833-8.

15. Bardai FH, D'Mello SR. Selective toxicity by HDAC3 in neurons: regulation by Akt and GSK3beta. J Neurosci. 2011;31:1746-51.

16. Rai M, Soragni E, Jenssen K, Burnett R, Herman D, Coppola G, Geschwind $\mathrm{DH}$, Gottesfeld JM, Pandolfo M. HDAC inhibitors correct frataxin deficiency in a Friedreich ataxia mouse model. PLoS ONE. 2008;3:e1958.

17. Jia H, Pallos J, Jacques V, Lau A, Tang B, Cooper A, Syed A, Purcell J, Chen Y, Sharma S, Sangrey GR, Darnell SB, Plasterer H, Sadri-Vakili G, Gottesfeld JM, Thompson LM, Rusche JR, Marsh JL, Thomas EA. Histone deacetylase (HDAC) inhibitors targeting HDAC3 and HDAC1 ameliorate polyglutamine-elicited phenotypes in model systems of Huntington's disease. Neurobiol Dis. 2012:46:351-61.

18. Hockly E, Richon VM, Woodman B, Smith DL, Zhou X, Rosa E, Sathasivam K, Ghazi-Noori S, Mahal A, Lowden PA, Steffan JS, Marsh JL, Thompson LM, Lewis CM, Marks PA, Bates GP. Suberoylanilide hydroxamic acid, a histone deacetylase inhibitor, ameliorates motor deficits in a mouse model of Huntington's disease. Proc Natl Acad Sci USA. 2003;100:2041-6.

19. Steffan JS, Bodai L, Pallos J, Poelman M, McCampbell A, Apostol BL, Kazantsev A, Schmidt E, Zhu YZ, Greenwald M, Kurokawa R, Housman DE, Jackson GR, Marsh JL, Thompson LM. Histone deacetylase inhibitors arrest polyglutamine-dependent neurodegeneration in Drosophila. Nature. 2001;413:739-43.

20. Schmitt HM, Pelzel HR, Schlamp CL, Nickells RW. Histone deacetylase 3 (HDAC3) plays an important role in retinal ganglion cell death after acute optic nerve injury. Mol Neurodegener. 2014;9:39.

21. Han KA, Shin WH, Jung S, Seol W, Seo H, Ko C, Chung KC. Leucine-rich repeat kinase 2 exacerbates neuronal cytotoxicity through phosphorylation of histone deacetylase 3 and histone deacetylation. Hum Mol Genet. 2017;26:1-18. 
22. Krishna K, Behnisch T, Sajikumar S. Inhibition of histone deacetylase 3 restores amyloid-beta oligomer-induced plasticity deficit in hippocampal CA1 pyramidal neurons. J Alzheimers Dis. 2016;51:783-91.

23. Mullican SE, Gaddis CA, Alenghat T, Nair MG, Giacomin PR, Everett LJ, Feng D, Steger DJ, Schug J, Artis D, Lazar MA. Histone deacetylase 3 is an epigenomic brake in macrophage alternative activation. Genes Dev. 2011;25:2480-8.

24. You SH, Liao X, Weiss RE, Lazar MA. The interaction between nuclear receptor corepressor and histone deacetylase 3 regulates both positive and negative thyroid hormone action in vivo. Mol Endocrinol. 2010;24:1359-67.

25. Feng D, Liu T, Sun Z, Bugge A, Mullican SE, Alenghat T, Liu XS, Lazar MA. A circadian rhythm orchestrated by histone deacetylase 3 controls hepatic lipid metabolism. Science. 2011;331:1315-9.

26. Barski A, Cuddapah S, Cui K, Roh TY, Schones DE, Wang Z, Wei G, Chepelev I, Zhao K. High-resolution profiling of histone methylations in the human genome. Cell. 2007;129:823-37.

27. Lin Y, Bloodgood BL, Hauser JL, Lapan AD, Koon AC, Kim TK, Hu LS, Malik AN, Greenberg ME. Activity-dependent regulation of inhibitory synapse development by Npas4. Nature. 2008;455:1198-204.

28. Rudenko A, Dawlaty MM, Seo J, Cheng AW, Meng J, Le T, Faull KF, Jaenisch $\mathrm{R}$, Tsai LH. Tet1 is critical for neuronal activity-regulated gene expression and memory extinction. Neuron. 2013;79:1109-22.

29. Ramamoorthi K, Fropf R, Belfort GM, Fitzmaurice HL, McKinney RM, Neve RL, Otto T, Lin Y. Npas4 regulates a transcriptional program in CA3 required for contextual memory formation. Science. 2011;334:1669-75.

30. Jaehne EJ, Klaric TS, Koblar SA, Baune BT, Lewis MD. Effects of Npas4 deficiency on anxiety, depression-like, cognition and sociability behaviour. Behav Brain Res. 2015;281:276-82.

31. Floor K, Baroy T, Misceo D, Kanavin OJ, Fannemel M, Frengen E. A 1 Mb de novo deletion within 11q13.1q13.2 in a boy with mild intellectual disability and minor dysmorphic features. Eur J Med Genet. 2012;55:695-9.

32. Ebert $\mathrm{DH}$, Greenberg ME. Activity-dependent neuronal signalling and autism spectrum disorder. Nature. 2013;493:327-37.

33. Moser M, Knoth R, Bode C, Patterson C. LE-PAS, a novel Arnt-dependent HLH-PAS protein, is expressed in limbic tissues and transactivates the CNS midline enhancer element. Brain Res Mol Brain Res. 2004;128:141-9.

34. Ooe N, Motonaga K, Kobayashi K, Saito K, Kaneko H. Functional characterization of basic helix-loop-helix-PAS type transcription factor NXF in vivo: putative involvement in an "on demand" neuroprotection system. J Biol Chem. 2009;284:1057-63.

35. Choy FC, Klaric TS, Koblar SA, Lewis MD. The role of the neuroprotective factor Npas4 in cerebral ischemia. Int J Mol Sci. 2015;16:29011-28.

36. Zhang SJ, Zou M, Lu L, Lau D, Ditzel DA, Delucinge-Vivier C, Aso Y, Descombes $\mathrm{P}$, Bading $\mathrm{H}$. Nuclear calcium signaling controls expression of a large gene pool: identification of a gene program for acquired neuroprotection induced by synaptic activity. PLoS Genet. 2009;5:e1000604.

37. Hester I, McKee S, Pelletier P, Thompson C, Storbeck C, Mears A, Schulz JB, Hakim AA, Sabourin LA. Transient expression of Nxf, a bHLH-PAS transactivator induced by neuronal preconditioning, confers neuroprotection in cultured cells. Brain Res. 2007;1135:1-11.

38. Woitecki AM, Muller JA, van Loo KM, Sowade RF, Becker AJ, Schoch S. Identification of synaptotagmin 10 as effector of NPAS4-mediated protection from excitotoxic neurodegeneration. J Neurosci. 2016;36:2561-70.

39. Mitre M, Mariga A, Chao MV. Neurotrophin signalling: novel insights into mechanisms and pathophysiology. Clin Sci. 2017;131:13-23.

40. He YY, Zhang $X Y$, Yung WH, Zhu JN, Wang JJ. Role of BDNF in central motor structures and motor diseases. Mol Neurobiol. 2013;48:783-93.

41. Lipsky RH, Marini AM. Brain-derived neurotrophic factor in neuronal survival and behavior-related plasticity. Ann N Y Acad Sci. 2007;1122:130-43.

42. Aid T, Kazantseva A, Piirsoo M, Palm K, Timmusk T. Mouse and rat BDNF gene structure and expression revisited. J Neurosci Res. 2007:85:525-35.

43. Sharma D, Kim MS, D'Mello SR. Transcriptome profiling of expression changes during neuronal death by RNA-Seq. Exp Biol Med. 2015;240:242-51.

44. Louis Sam Titus ASC, YusuffT, Cassar M, Thomas E, Kretzschmar D, D'Mello SR. Reduced expression of Foxp 1 as a contributing factor in Huntington's disease. J Neurosci. 2017;37:6575-87.

45. Verma P, Pfister JA, Mallick S, D'Mello SR. HSF1 protects neurons through a novel trimerization- and HSP-independent mechanism. J Neurosci. 2014:34:1599-612.
46. Valouev A, Johnson Ds Fau - Sundquist A, Sundquist A Fau - Medina C, Medina C Fau - Anton E, Anton E Fau - Batzoglou S, Batzoglou S Fau Myer s RM, Myers Rm Fau - Sidow A, Sidow A. Genome-wide analysis of transcription factor binding sites based on ChIP-Seq data.

47. D'Mello SR, Galli C, Ciotti T, Calissano P. Induction of apoptosis in cerebellar granule neurons by low potassium: inhibition of death by insulin-like growth factor I and cAMP. Proc Natl Acad Sci USA. 1993;90:10989-93.

48. Farnham PJ. Insights from genomic profiling of transcription factors. Nat Rev Genet. 2009;10:605-16.

49. Visel A, Blow MJ, Li Z, Zhang T, Akiyama JA, Holt A, Plajzer-Frick I, Shoukry M, Wright C, Chen F, Afzal V, Ren B, Rubin EM, Pennacchio LA. ChIPseq accurately predicts tissue-specific activity of enhancers. Nature. 2009;457:854-8.

50. Martinowich K, Hattori D, Wu H, Fouse S, He F, Hu Y, Fan G, Sun YE. DNA methylation-related chromatin remodeling in activity-dependent BDNF gene regulation. Science. 2003;302:890-3.

51. Tao X, Finkbeiner S, Arnold DB, Shaywitz AJ, Greenberg ME. Ca2+ influx regulates BDNF transcription by a CREB family transcription factordependent mechanism. Neuron. 1998;20:709-26.

52. Shieh PB, Hu SC, Bobb K, Timmusk T, Ghosh A. Identification of a signaling pathway involved in calcium regulation of BDNF expression. Neuron. 1998;20:727-40.

53. Tao X, West Ae Fau - Chen WG, Chen Wg Fau - Corfas G, Corfas G Fau Greenberg ME, Greenberg ME. A calcium-responsive transcription factor, CaRF, that regulates neuronal activity-dependent expression of BDNF.

54. Chen WG, West AE, Tao X, Corfas G, Szentirmay MN, Sawadogo M, Vinson C, Greenberg ME. Upstream stimulatory factors are mediators of $\mathrm{Ca} 2+-$ responsive transcription in neurons. J Neurosci. 2003;23:2572-81.

55. Maya-Vetencourt JF. Activity-dependent NPAS4 expression and the regulation of gene programs underlying plasticity in the central nervous system. Neural Plast. 2013;2013:683909.

56. Sun $X$, Lin Y. Npas4: linking neuronal activity to memory. Trends Neurosci. 2016;39:264-75.

57. Saha RN, Wissink EM, Bailey ER, Zhao M, Fargo DC, Hwang JY, Daigle KR, Fenn JD, Adelman K, Dudek SM. Rapid activity-induced transcription of Arc and other IEGs relies on poised RNA polymerase II. Nat Neurosci. 2011;14:848-56.

58. Madabhushi R, Gao F, Pfenning AR, Pan L, Yamakawa S, Seo J, Rueda R, Phan TX, Yamakawa H, Pao PC, Stott RT, Gjoneska E, Nott A, Cho S, Kellis $\mathrm{M}$, Tsai LH. Activity-induced DNA breaks govern the expression of neuronal early-response genes. Cell. 2015;161:1592-605.

59. Pruunsild P, Sepp M, Orav E, Koppel I, Timmusk T. Identification of cis-elements and transcription factors regulating neuronal activity-dependent transcription of human BDNF gene. J Neurosci. 2011;31:3295-308.

60. Bloodgood BL, Sharma N, Browne HA, Trepman AZ, Greenberg ME. The activity-dependent transcription factor NPAS4 regulates domain-specific inhibition. Nature. 2013:503:121-5.

61. Zuccato C, Cattaneo E. Brain-derived neurotrophic factor in neurodegenerative diseases. Nat Rev Neurol. 2009;5:311-22.

62. Nott A, Cheng J, Gao F, Lin YT, Gjoneska E, Ko T, Minhas P, Zamudio AV, Meng J, Zhang F, Jin P, Tsai LH. Histone deacetylase 3 associates with MeCP2 to regulate FOXO and social behavior. Nat Neurosci. 2016;19:1497-505.

63. Sartor GC, Malvezzi AM, Kumar A, Andrade NS, Wiedner HJ, Vilca SJ, Janczura KJ, Bagheri A, Al-Ali H, Powell SK, Brown PT, Volmar CH, Foster TC, Zeier Z, Wahlestedt C. Enhancement of BDNF expression and memory by HDAC inhibition requires BET bromodomain reader proteins. J Neurosci. 2019;39:612-26.

64. Sleiman SF, Henry J, Al-Haddad R, El Hayek L, Abou Haidar E, Stringer T, Ulja D, Karuppagounder SS, Holson EB, Ratan RR, Ninan I, Chao MA-O. Exercise promotes the expression of brain derived neurotrophic factor (BDNF) through the action of the ketone body beta-hydroxybutyrate. Elife. 5:e15092. https://doi.org/10.7554/eLife.15092.

65. Janczura KJ, Volmar CH, Sartor GC, Rao SJ, Ricciardi NR, Lambert G, Brothers SP, Wahlestedt C. Inhibition of HDAC3 reverses Alzheimer's diseaserelated pathologies in vitro and in the $3 \times \mathrm{Tg}-\mathrm{AD}$ mouse model. Proc Natl Acad Sci USA. 2018;115:E11148-57.

66. Zhao H, Alam A, San CY, Eguchi S, Chen Q, Lian Q, Ma D. Molecular mechanisms of brain-derived neurotrophic factor in neuro-protection: recent developments. Brain Res. 2017;1665:1-21. 
67. Brunet A, Bonni A, Zigmond MJ, Lin MZ, Juo P, Hu LS, Anderson MJ, Arden KC, Blenis J, Greenberg ME. Akt promotes cell survival by phosphorylating and inhibiting a Forkhead transcription factor. Cell. 1999;96:857-68.

68. Bonni A, Brunet A, West AE, Datta SR, Takasu MA, Greenberg ME. Cell survival promoted by the Ras-MAPK signaling pathway by transcriptiondependent and -independent mechanisms. Science. 1999;286:1358-62

69. Mao Z, Bonni A, Xia F, Nadal-Vicens M, Greenberg ME. Neuronal activitydependent cell survival mediated by transcription factor MEF2. Science. 1999;286:785-90.

70. Datta SR, Dudek H, Tao X, Masters S, Fu H, Gotoh Y, Greenberg ME. Akt phosphorylation of BAD couples survival signals to the cell-intrinsic death machinery. Cell. 1997;91:231-41.

71. Dudek H, Datta SR, Franke TF, Birnbaum MJ, Yao R, Cooper GM, Segal RA, Kaplan DR, Greenberg ME. Regulation of neuronal survival by the serinethreonine protein kinase Akt. Science. 1997;275:661-5.

72. Bekinschtein $\mathrm{P}$, Cammarota M, Medina $\mathrm{JH}$. BDNF and memory processing. Neuropharmacology. 2014;76(Pt C):677-83.

73. Cunha C, Brambilla R, Thomas KL. A simple role for BDNF in learning and memory? Front Mol Neurosci. 2010;3:1.

74. Leal G, Afonso PM, Salazar IL, Duarte CB. Regulation of hippocampal synaptic plasticity by BDNF. Brain Res. 2015;1621:82-101.

75. McQuown SC, Barrett RM, Matheos DP, Post RJ, Rogge GA, Alenghat T, Mullican SE, Jones S, Rusche JR, Lazar MA, Wood MA. HDAC3 is a critical negative regulator of long-term memory formation. J Neurosci. 2011;31:764-74.

76. McQuown SC, Wood MA. HDAC3 and the molecular brake pad hypothesis. Neurobiol Learn Mem. 2011;96:27-34.

77. Rogge GA, Singh H, Dang R, Wood MA. HDAC3 is a negative regulator of cocaine-context-associated memory formation. J Neurosci. 2013;33:6623-32.
78. Malvaez M, McQuown SC, Rogge GA, Astarabadi M, Jacques V, Carreiro S, Rusche JR, Wood MA. HDAC3-selective inhibitor enhances extinction of cocaine-seeking behavior in a persistent manner. Proc Natl Acad Sci USA. 2013;110:2647-52.

79. Jia H, Morris CD, Williams RM, Loring JF, Thomas EA. HDAC inhibition imparts beneficial transgenerational effects in Huntington's disease mice via altered DNA and histone methylation. Proc Natl Acad Sci USA. 2015;112:E56-64

80. Thomas EA. Focal nature of neurological disorders necessitates isotype-selective histone deacetylase (HDAC) inhibitors. Mol Neurobiol. 2009;40:33-45.

81. Thomas EA. Involvement of HDAC1 and HDAC3 in the pathology of polyglutamine disorders: therapeutic implications for selective HDAC1/ HDAC3 inhibitors. Pharmaceuticals. 2014;7:634-61.

82. Norwood J, Franklin JM, Sharma D, D'Mello SR. Histone deacetylase 3 is necessary for proper brain development. J Biol Chem. 2014;289(50):34569-82.

83. Nair B, Wong-Riley MT. Transcriptional regulation of brain-derived neurotrophic factor coding exon IX: ROLE OF NUCLEAR RESPIRATORY FACTOR 2. J Biol Chem. 2016;291(43):22583-93.

\section{Publisher's Note}

Springer Nature remains neutral with regard to jurisdictional claims in published maps and institutional affiliations.
Ready to submit your research? Choose BMC and benefit from:

- fast, convenient online submission

- thorough peer review by experienced researchers in your field

- rapid publication on acceptance

- support for research data, including large and complex data types

- gold Open Access which fosters wider collaboration and increased citations

- maximum visibility for your research: over 100M website views per year

At BMC, research is always in progress.

Learn more biomedcentral.com/submissions 